\title{
ALTERAÇÕES DE COMPORTAMENTO DOS IDOSOS APÓS UM EVENTO ESTRESSOR E ANTES DO DIAGNÓSTICO DEMENCIAL: PERCEPÇÃO DO CUIDADOR FAMILIAR
}

CALABRO, M. - Universidade São Judas Tadeu - Mestrado em Ciências do Envelhecimento

ORTIZ, S.R.M.

\section{RESUMO}

O rápido processo de envelhecimento vem de encontro com o aumento da expectativa de vida. Neste contexto, pode-se dizer que quem vive mais tem maior probabilidade de surgimento de doenças demenciais, incapacitantes e evolutivas, e diante do curso do envelhecimento, os familiares perceberam alterações de comportamento após um evento estressor vivido pelo idoso, o que levou a impactar todo núcleo familiar. Esses idosos posteriormente foram diagnosticados a quadros demenciais, e assim, institucionalizados. Dessa forma, o presente trabalho teve como objetivo realizar um estudo de campo qualitativo, baseado em entrevistas narrativas de 12 familiares de idosos demenciados e institucionalizados onde foram coletadas informações acerca de eventos estressores e eventuais alterações no comportamento do idoso, antecedente ao diagnóstico demencial, pela percepção do familiar cuidador, por fim, encontramos resultados desvelando, se os familiares associaram as mudanças de comportamento a uma demência, e se sabiam lidar com a doença. Concluiu-se que todos os idosos sofreram mudança de comportamento após eventos estressores vivenciados antes do diagnóstico de demência, e que pela percepção dos familiares, entenderam que houve de fato uma possível correlação do evento com a potencialização do quadro, e que a maioria dos familiares não sabiam lidar com a doença. Pretende-se com este estudo, o incentivo à novos estudos acerca da importância de os familiares perceberem as alterações de comportamento dos idosos, e com isso, a possível antecipação do diagnóstico o que permitiria o estabelecimento de ações mais efetivas de tratamento.

Palavras-chave: Idosos; Demências; Envelhecimento; Comportamento do Idoso.

Agradecimentos: agradeço a Universidade São Judas Tadeu e aos professores que conduzem com tanta sabedoria, respeito e inspiração o Mestrado em Ciências do Envelhecimento, e agradeço imensamente à CAPES pela bolsa de estudos, pela qual me dá a oportunidade de frequentar o curso. 